\title{
Reframing service innovation: COVID-19 as a catalyst for imposed service innovation
}

\author{
Kristina Heinonen and Tore Strandvik \\ Department of Marketing, CERS Centre for Relationship Marketing and \\ Service Management, Hanken School of Economics, Helsinki, Finland
}

\begin{abstract}
Purpose - The empirical study draws on a crowdsourced database of 221 innovations associated with the COVID-19 pandemic.

Design/methodology/approach - Aside from the health and humanitarian crisis, the COVID-19 pandemic has caused an acute economic downturn in most sectors, forcing public and private organizations to rethink and reconfigure service provision. The paper introduces the concept of imposed service innovation as a new strategic lens to augment the extant view of service innovation as a primarily discretionary activity.

Findings - The identified imposed service innovations were assigned to 11 categories and examined in terms of their strategic horizon and strategic stretch. The innovations are characterized by spatial flexibility, social and health outreach and exploitation of technology.

Research limitations/implications - As a new area of service innovation research, imposed service innovations highlight strategic issues that include the primacy of customers and the fragility of institutions. Practical implications - Situations involving imposed service innovation represent opportunities for rapid business development when recognized as such. A severe disruption such as a pandemic can catalyze managerial rethinking as organizations are forced to look beyond their existing business strategies.

Social implications - As a strategic response to severe disruption of institutions, markets and service offerings, imposed service innovations afford opportunities to implement transformation and enhance wellbeing. This novel strategic lens foregrounds a societal account of service innovation, emphasizing societal relevance and context beyond the challenges of business viability alone.

Originality/value - While extant service innovation research has commonly focused on discretionary activities that enable differentiation and growth, imposed service innovations represent actions for resilience and renewal.
\end{abstract}

Keywords Service innovation, Pandemic, Disruption, Dynamic capabilities, Resilience

Paper type Research paper

\section{Introduction}

As a global health and humanitarian crisis, the COVID-19 pandemic affected society at the macro, meso and micro levels (Finsterwalder and Kuppelwieser, 2020), and its economic and societal effects are unprecedented. For public and private organizations, a crisis such as a pandemic is a strategic challenge, and the associated disruption of demand and capacity, increased uncertainty and financial instability forces a reassessment and restructuring of business operations (Cortez and Johnston, 2020; Kabadayi et al., 2020). Managerial attention is required to assess how the disruption affects customers and employees (Klaus and Manthiou, 2020; Lang et al., 2020; Sheth, 2020; Tuzovic and Kabadayi, 2020). Service innovation to improve existing services and create new ones is one way of coping with the crisis. The

(C) Kristina Heinonen and Tore Strandvik. Published by Emerald Publishing Limited. This article is published under the Creative Commons Attribution (CC BY 4.0) licence. Anyone may reproduce, distribute, translate and create derivative works of this article (for both commercial and non-commercial purposes), subject to full attribution to the original publication and authors. The full terms of this licence may be seen at http://creativecommons.org/licences/by/4.0/legalcode

This paper forms part of a special section "The Coronavirus Crisis and Beyond: Implications for Service Research and Practice" guest edited by Prof. Volker G. Kuppelwieser and Dr. Jörg Finsterwalder.
Imposed service innovation and COVID-19

Received 9 May 2020 Revised 11 June 2020 25 June 2020

Accepted 26 June 2020

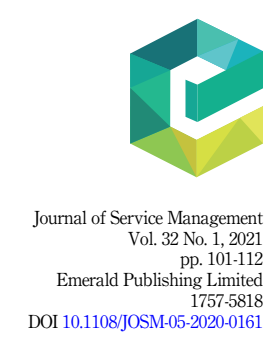


JOSM 32,1

102

pandemic prompted extraordinary interest in innovation, including calls to inspire, initiate and coordinate innovations beyond those already designed and implemented. Some of these initiatives were global or national in scope; others emerged at organization or company level. Organizations typically face disruptive changes in their operating environment that emerge at a relatively slow pace and with uneven effects, as for instance in the case of digitalization or the challenges of sustainability. Although challenging, these are moderate disruptions when compared to the unprecedented rapidity and global scale of the pandemic and its aftermath, which impacted all sectors and levels of society. This crisis created a completely new context for service innovation beyond anything in the extant research.

Service innovation has typically been considered a key factor in organizational differentiation and growth (Feng et al., 2020; Helkkula et al., 2018; Kowalkowski and Witell, 2020) and a matter of management discretion. We contend here that a crisis like a pandemic shifts the emphasis from discretionary to forced activity, often to ensure the organization's survival and resilience. This has quite dramatic consequences, elevating service innovation to a core strategic issue. Applying a strategic lens to service innovation in disruptive contexts, we have developed a conceptual model to capture how organizations have responded to this global crisis.

The study sought to articulate and explore what we characterize as imposed service innovation as a novel phenomenon that contrasts with the common idea of service innovation as a primarily discretionary activity. We argue that a crisis like COVID-19 accelerated innovation not because organizations want to innovate but because they had to. From a strategic perspective, imposed service innovation mitigates negative consequences by triggering a change of mindset and stimulating business opportunities that would not have been considered under normal circumstances (e.g., Nenonen and Storbacka, 2020; Batat, 2020). Our approach emphasizes (1) service innovation as an attempt to retain customers in changing conditions; (2) customer value creation as the foundation for success and (3) strategic reorientation as a managerial response to disruptive market challenges. The paper assesses the implications of the crisis for organizations and suggests avenues for further research.

\section{Service innovation research and imposed service innovation}

Recent comprehensive reviews of service and service innovation research mainly describe the state of the art before the COVID-19 pandemic. Some of these reviews categorize service innovations in terms of underlying assumptions and epistemologies; for example, Helkkula et al. (2018) identified four archetypes: output-based, process-based, experiential and systemic, highlighting features, processes and actor configurations. Kowalkowski and Witell (2020) anticipate that these archetypes will prevail. Reflecting on the current status of service innovation research, Gustafsson et al. (2020) expressed concerns about the diversity of concepts and approaches and the lack of cumulative research. In their overview of service design and innovation research, Antons and Breidbach (2018) noted this diversity and suggested that different topics should be combined to explore, for example, how dynamic capabilities enable organizations to engage in service innovation and business model development. Furrer et al. (2020) reviewed service research over a period of 27 years and again noted the diversity of research themes. Their synthesis identified a strong emphasis on operational and organizational issues.

These reviews characterize service innovation research as diverse in approaches and concepts but narrow in empirical scope. We argue that a strategic lens can provide a more extensive account of service innovation beyond current theorizing and that this strategic perspective is needed in disruptive circumstances such as a pandemic. To that end, we propose to extend the service innovation literature by introducing conceptual frames from strategic management to capture the strategic role of service innovation in disruptive contexts. We contend that the disruptive consequences of the pandemic trigger a reframing of service innovation that is also relevant in other instances of critical disruption. 
Because disruption is an important topic in strategic management, this research can contribute to studies of service innovation. For example, research on dynamic capabilities (Teece, 2007; Baden-Fuller and Teece, 2020) and managerial sense-making (e.g., Hamel and Prahalad, 1994) highlights the importance of noticing and responding to changing conditions by "... sensing. . . opportunities and persuading others that such opportunities are worth pursuing speedily with the resources at hand supplemented by those of alliance partners" (Baden-Fuller and Teece, 2020, p. 2). Similarly, a recent managerially oriented framework for value proposition development includes strategic consideration of the fit between business model and customer needs in dynamic markets (Payne et al., 2020). In normal times, business models and service offerings are established and fine-tuned to customers and competitors in the industry. At times of severe market disruption, offerings and business models can become obsolete as a consequence of changes in customer behavior and value creation patterns. It then becomes a matter of urgency to challenge managers' mindsets in pursuit of an effective strategic response. The strategic management literature suggests that managerial sensemaking plays a key role in responding to disruption (e.g. Baden-Fuller and Teece, 2020).

We coined the term imposed service innovation to highlight the strategic and progressive actions required following extreme disruptive changes in the surrounding environment. The term denotes critical and enforced responses to sudden and unforeseen disruptions that require transformation of the service offering and business model within the constraints of available resources and operations. In contrast, existing studies of service innovation have typically focused on discretionary service innovations, which are effectively the opposite; as proactive responses to gradual change in the surrounding business environment and marketplace, innovations of this kind are driven by differentiation and growth incentives and are initiated at the organization's own discretion, with less immediate time pressure. The notion of imposed service innovation introduces a novel strategic lens that informed our empirical investigation of innovations prompted by the COVID-19 pandemic.

\section{Method}

The empirical study was conducted in collaboration with the Dutch consumer foresight company TrendWatching and its Business of Purpose initiative. To that end, we accessed a database containing innovations triggered by COVID-19, which is available publicly on www.covidinnovations.com. Initiated in March 2020, the database includes voluntary crowdsourced information submitted to TrendWatching regarding innovations related to the pandemic. Each record contains a time tag, description, and categorization by sector. By April 27, the database included 702 innovations covering 24 sectors; the largest categories were health and fitness (103), food and beverages (76), information technology (75), media and entertainment (74) and retail (57). The dataset included 179 duplicates (innovations tagged in two or three categories), and these were removed. Applying the elimination criteria (described below) led to the removal of 385 innovations, and the final dataset included 221 innovations. The database represents a unique collection of innovations imposed as a result of the pandemic, which are diverse in terms of themes and strategic characteristics. The intention was not to assess the uniqueness and success of these innovations but to explore the nature of responses to the pandemic. While recognizing the urgent need for medical and healthcare innovations, we excluded those related to vaccines, medicine or medical services and equipment developed to treat the disease. We also excluded innovative protective gear, sanitization products, ventilators, and hands-free devices designed to mitigating the direct consequences of the pandemic. We furthermore include exclusively innovations for consumers and citizens as users and customers.

The findings were coded and analyzed by the authors. Each innovation was assigned to thematic categories that emerged inductively and related to the empirical context and content 
JOSM

32,1

104

of the innovation. To capture customer relevance, we focused on the technical, functional, temporal, spatial and social value components of the innovations (Heinonen et al., 2013). Simultaneously, we coded the innovations along two strategic management dimensions, which we labeled strategic stretch and strategic horizon (Figure 1). These are grounded in theories of dynamic capabilities and managerial sense-making (Hamel and Prahalad, 1994; Teece, 2007; Baden-Fuller and Teece, 2020). Strategic stretch refers to the degree of change in sense-making, business model and resource requirements (ranging from low-adjustment of existing business model and offerings - to high - major changes and reconfiguration of business model, offering, and strategy). Strategic horizon refers to the response timeframe (ranging from short-term -relevant during and immediately after the crisis - to long-termlikely to extend beyond and remain in place after the crisis). In combination, these two dimensions indicate the extent of strategic rethinking required to launch the innovation.

\section{Findings: imposed service innovations}

The thematic categories and the strategic characteristics of the innovations are described below. The number of innovations in each category is provided only for descriptive purposes.

\section{Thematic categories}

The empirical context and content of the innovations generated 11 thematic categories, each of which is illustrated by representative examples.

Social initiative innovations $(N=33)$. Social initiative innovations rest on individuals' generosity to local businesses, the environment and citizen groups. Many of these innovations have a social dimension, focusing on societal well-being by providing platforms for economic or behavioral actions in the community, including websites for making online donations, expressing gratitude or offering support. Examples include the US startup Forward [1], a primary care service that supports nonCOVID patients during lockdown; the Kindness of Strangers platform [2], which enables individuals to donate their expertise to others and the Caremonger [3] and NextDoor [4] platforms, which connect helpers with those in need of everyday assistance.

Delivery innovations $(N=32)$. A second category relates to contactless or remote delivery through robots, drive-through, or community-driven deliveries. For example, many Asian retailers use robots to deliver groceries. The French supermarket group Carrefour [5] collaborated with the on-demand meal delivery service Uber Eats to offer home groceries

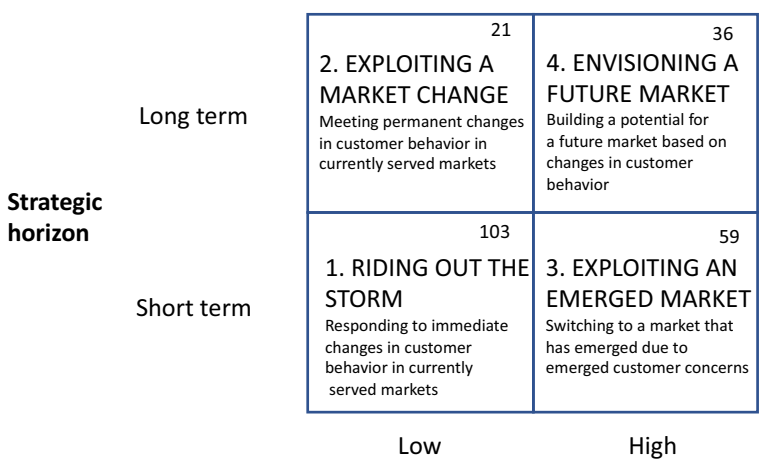


delivery. Supermarkets also began to offer online shopping with home delivery, turning their stores into order fulfillment sites. Similarly, many hotels, restaurants and bars now provide takeaway and drive-through options. Some restaurants have been transformed into so-called "dark" kitchens [6], where meals are made in isolation for delivery to customers. Other innovations relate to the timing of service delivery; for example, supermarkets offer online booking and scheduling [7], as well as dedicated shopping hours [8] for vulnerable customers. These innovations incorporate temporal and spatial value elements that focus on the time and location of service delivery and use.

Physical distancing innovations $(N=30)$. Physical distancing innovations ensure the implementation of health and safety measures and sufficient distances between individuals, based on both tangible and intangible technical features. Examples include wearables and devices such as the mechanical Fortum Vipu [9] (for opening doors without touching the handle); the smart device Aura Aware, [10] which helps to maintain a safe physical distance from others and the SafeHands bracelet [11] for monitoring facial contact behavior. Intangible physical distancing innovations include mobile phone apps such as Snapchat's My Social Distance AR [12] lens, a visual aid to help maintain safe physical distancing in public spaces. The spatial and social value components of these innovations focus on the spaces and settings in which individuals move.

Remote presence innovations $(N=26)$. Remote presence innovations enable users to be mentally present at one location while physically located at another place, as in virtual travel and experiencing cultural locations from one's own home. Restaurants, artists, and other service providers also offer applications that allow one to experience their services virtually or remotely. For example, the UK brewery Signature Brew developed the product bundle Pub In A Box [13] to bring the pub to customers' homes. Others using technology to support remote real-time presence at different venues include Japanese student graduation ceremonies involving Minecraft [14] or robots [15]; virtual dinner tables by the Finnish dairy company Valio [16]; and virtual office parties [17], theme hangouts [18], and group events [19]. The location-specific and real-time components of these innovations offer high levels of temporal, spatial and social value.

Entertainment innovations $(N=21)$. These innovations provide entertaining, relaxing and pleasurable content such as live online music performances and sports events. Examples include the virtual NBA 2K tournament [20], the livestreamed SXSW festival [21], and ATP Tennis Tour [22] online betting. These innovations often involve diverse groups of content providers, retailers and NGOs; offering engaging activities to counteract boredom, they provide functional and social value.

Health and well-being innovations $(N=20)$. Mental health innovations bring meaning and reduce stress and anxiety. Examples include Wanderble's Mindfulness in Isolation [23] course; the mental health app My Possible Self [24], offering psychological strategies and coping skills and Artezen's creative therapy workshops [25]. Other less obvious innovations in this category include retailers that have transformed their customer service channels to provide mental health support [26].

Physical health innovations that encourage individuals to move and keep physically healthy include StepSetGo [27]- a series of challenges to encourage indoor steps - and Moments2Move, [28] with regular browser alerts to encourage movement. The KeepMoving platform [29] enables users to run the Düsseldorf Marathon without exposure to others, tracking their movement on an indoor treadmill or outside on a running track. Health and well-being innovations provide functional value by supporting everyday life processes.

Professional consultation innovations $(N=18)$. Many retailers have created online services to complement declining store sales. These professional consultation innovations draw on the in-store customer service experience to provide guidance, resources and support for customer self-service. For example, the beauty brand Kiehl's turned its sales personnel into 
JOSM 32,1

106

virtual consultants [30] to provide individuals with customized consultation and support via video or text chat. Clinicians are also using medical software to offer patients contact-free consultations, real-time diagnostics [31], and medical examinations. Bakeries and restaurants have developed resources and self-service kits [32] to support in-home meal preparation. All of these innovations provide spatial and functional value by offering customized services that meet specific personal needs in a customer's own home.

Social connection innovations $(N=18)$. While remote presence innovations provide access to virtual experiences, social connection innovations focus on connecting individuals and fostering a sense of coexistence. Many such innovations address individual relationships and communication; the Goodnight Zoom [33] storytelling app, Google's Vemos [34] and Netflix Party [35] support joint streaming of movies and TV series, and this category also includes social gaming and virtual dating innovations [36]. These innovations incorporate a clear social value component.

Education innovations $(N=11)$. Education innovations developed by diverse organizations with pedagogical intentions support distance learning and knowledge development. Examples include educational platforms [37] developed by zoos and museums to share livestreams, behind-the-scenes videos and interactive activities for learning about animals or the arts, as well as remote cooking [38], music classes and business webinars. All of these provide technical value in terms of information and educational content, and their synchronous live content also provides temporal value.

COVID-19 experience innovations $(N=8)$. COVID-19 experience innovations are a collection of manifestations of individuals' and communities' experiences of the pandemic. Examples include the Coronavirus Chronicles [39], which collects personal stories from people around the world and the crowdsourced Futurity platform [40], a live digital archive of people's experiences during the pandemic. COVID-themed foods and treats such as toilet paper cakes [41] have also been developed by restaurants and bakeries. While some of these innovations have general relevance, others target specific groups; for example, the Unfinished Stories [42] platform collects student experiences of COVID-19. These innovations offer outcome-focused and social elements.

Public innovations $(N=3)$. Some innovations were created by the public sector in response to urgent societal challenges, mainly to redirect existing public resources for the benefit of the vulnerable. Although this is the smallest category, these innovations demonstrate the willingness and ability of public and government actors to respond in innovative ways to community needs. Examples include the European Parliament app, which opens up spaces [43] for the homeless and another for recovering COVID patients. In France, public agencies are offering hotel accommodation and pop-up counselling [44] for victims of domestic violence.

\section{Imposed innovations: strategic ideal types}

Despite its pervasive nature, a crisis like the pandemic affects organizations unevenly, ranging from no effect to extreme negative effects. In the present case, the imposed innovations in the database can be categorized into ideal types that range from minor adjustment of the service offering to profound changes in the service offering or business model. Figure 1 summarizes the four ideal types, and the descriptions that follow are illustrated with a hair salon example.

In combination with the thematic analysis, this strategic categorization of innovations shows that all the thematic categories are present in all four types, indicating that all of these are possible options for any organization. Type 1 accounts for the largest number of service innovations, which is logical, as these are the least demanding to envision and implement. Type 4 represents the smallest number, indicating that more advanced situations require profound reflection and involve greater uncertainty. A common feature of these innovations is that they seem to reflect a latent demand. Organizations have sensed and discovered these 
before quickly identifying a solution that exploits and stretches their capabilities. In some cases, a new organization emerges from this process. Serving as a trigger, the pandemic has lent energy and direction to innovation work that is unlikely to have been initiated in normal circumstances.

Type 1. Short-time horizon/low strategic stretch $(N=103)$. The first type of service innovation addresses customers' immediate concerns and relates essentially to coping strategies for "riding out the storm." New services of this type modify or adjust existing services to meet the new requirements without changing the business model or strategy. A majority of these are social initiatives. Many address the immediate challenges of new modes of interaction and delivery; for example, restaurants offer takeaway services and grocery stores offer home delivery or pickup. This type also includes organizations cooperating to form small service systems for customers, as in the case of collaborative delivery systems involving taxi drivers and grocery stores. In the case of the hair salon, one example of this type is the use of face masks when interacting with clients.

Type 2. Long time horizon/low strategic stretch $(N=21)$. Innovations that address an ongoing customer concern in the new situation beyond the immediate present can achieve longer-term effects. In such cases, organizations seek to exploit changes in the market. For example, Facebook released a messaging app called Tuned [45] to enable couples to stay connected while physically separated, and this remote presence innovation may prove useful beyond the crisis. Hair salon innovations of this type would include making house calls to clients.

Type 3. Short time horizon/high strategic stretch $(N=59)$. This type of innovation addresses potential customer demand by using an organization's resources and capabilities to create a novel service that requires mental, strategic and operational reconfiguration. This type focuses on immediate emerging markets that may not persist beyond the crisis, using existing resources to enable service innovation. This may include cooperation with other companies or organizations in designing and providing the service offering and delivery. For example, German cities have redrawn road markings [46] to create safely distanced bike lanes, which they plan to remove after the crisis. An example from the hair salon might involve trimming dogs rather than cutting hair.

Type 4. Long time horizon/high strategic stretch $(N=36)$. Innovations that remain relevant beyond the crisis reflect more permanent changes in customer aspirations, practices and logics that shift their use of services and processes of value creation. These innovations require strong envisioning to adapt current capabilities and resources to a novel offering. An example is the home leisure trend [47], where individuals upgrade their clothing while spending time in isolation. This trend may persist if there is lasting interest in elegant home clothing. Delivery innovations based on self-service technologies [48] such as vending machines for face masks and hot meals, as well as unmanned grocery stores, may also be of lasting value to individuals. In the case of the hair salon, this might involve training customers to cut their own or others' hair.

\section{Discussion}

A massive disruption such as a pandemic can serve as an effective catalyst for service innovations. Our empirical study demonstrates how the pandemic forced organizations to stretch beyond existing business strategies. These imposed service innovations are characterized by spatial flexibility, social and health outreach and technology exploitation as the pandemic triggers changes of enduring relevance that include motives for service innovation; managerial sense-making; the role of customers; the role of external restrictions and the dynamics of institutions, relationships and practices. These have previously been taken largely for granted rather than problematized as service innovation focused on stability and linear development. The emerging innovations are organization-specific responses to 
JOSM 32,1

108

disruption, attesting to the organizations' dynamic capabilities. In short, the question of whether these are "new" or different, either globally or within an industry, is less interesting than whether they are relevant to customers in terms of value creation. Still, many of the imposed service innovations that emerged from the pandemic are focused on the short term riding out the storm - rather than envisioning future market opportunities.

Critical reflection on the service literature's implicit emphasis on discretionary innovations provides several insights. The concept of imposed service innovations highlights disruptive forces of change that must be viewed through a strategic lens, complementing the archetypal structure of innovations based on features, processes and actor configurations (Helkkula et al., 2018; Snyder et al., 2016). As an alternative conceptual frame, the idea of imposed service innovation addresses some of the gaps in the existing literature, such as the primacy of customers and the fragility of institutions. Highlighting the strategic role of service innovation in the context of dynamics, time, space and the organizations' dynamic capabilities, this new arena for service innovation research focuses on relevance rather than the mere novelty of the innovation. The strategic lens also transforms the notion of service innovation by advancing a societal account that emphasizes societal relevance and context rather than challenges of business viability alone.

For managers, imposed service innovations accelerate critical reflection by challenging baseline assumptions regarding the existing business model and service offerings, as well as current and potential customers. As a consequence of severe disruptions, imposed service innovation are actions for resilience and renewal, rather than differentiation and growth. This in turn requires greater attention and sensitivity to fundamentals in the surrounding environment. Public and private organizations need to (1) recognize collaborative opportunities in the disrupted situation, (2) focus on understanding changed customer contexts and reasoning and (3) develop the agility of the organizations' capabilities and network of partners. Crisis accentuates the primacy of customers and the recognition that successful service innovations are built on understanding customers and their contexts; without customers, there is no business (Levitt, 1960; Drucker, 1974). In practice, imposed service innovation can inspire new directions and approaches to innovation.

\section{Limitations and further research}

This study would benefit from longitudinal data on imposed service innovations. The present data refer to developments emerging from the COVID-19 pandemic, and at the time of writing, their success remains unclear, either for the organization or from the perspective of customers and users. Additionally, the study provides no information about service development and design processes or organizational reasoning. These limitations clearly invite further research. In line with Kabadayi et al. (2020), future research should also examine how variations in national and local government approaches to the pandemic have created different business circumstances, influencing how companies can or must adjust their operations. In general, the specific reasons and triggers for imposed service innovations, including policies, financial challenges and customer reactions, indicate another direction for future research. Building on the notions of sensitivity to the surrounding environment and the changed context among individuals and in societies, further research should also address how imposed service innovations trigger new insights that traditional discretionary service innovation fails to disclose.

\section{Notes}

1. https://www.covidinnovations.com/home/07042020/us-health-tech-startup-forward-launchesforward-at-home-a-primary-care-service 
2. https://www.covidinnovations.com/home/31032020/kindness-of-strangers-lets-skilled-peopledonate-30-minutes-of-their-time-to-people-in-need-of-help

3. https://www.covidinnovations.com/home/15042020/digital-agency-isobar-australia-launchescaremonger-app-to-enable-people-to-help-out-their-neighbours

4. https:/www.covidinnovations.com/home/01042020/us-online-platform-nextdoor-enables-peopleto-connect-with-neighbours-in-need

5. https://www.covidinnovations.com/home/06042020/uber-eats-and-delivery-hero-branch-out-tosupplying-groceries-to-customers-stuck-at-home

6. https:/www.covidinnovations.com/home/15042020/minnesota-chefs-from-unitedhealth-groupnow-cook-from-home-for-loaves-and-fishes-distribution-sites

7. https://www.covidinnovations.com/home/restaurant-booking-platform-open-table-developssupermarket-bookings

8. https://www.covidinnovations.com/home/22032020/woolworths-in-australia-introduce-dedicatedshopping-hour-for-the-elderly-and-people-with-disabilities

9. https://www.covidinnovations.com/home/06042020/uber-eats-and-delivery-hero-branch-out-tosupplying-groceries-to-customers-stuck-at-home

10. https://www.covidinnovations.com/home/15042020/new-technology-company-aura-awareproduces-smart-distance-awareness-device

11. https://www.covidinnovations.com/home/american-company-safehands-launches-immotouch-thebracelet-that-vibrates-when-you-put-your-hands-to-your-face

12. https://www.covidinnovations.com/home/14042020/snap-safe-is-a-new-snapchat-ar-lens-to-helppeople-keep-a-safe-physical-distance

13. https://www.covidinnovations.com/home/20042020/uk-brewery-signature-brew-introduces-pubin-a-box-a-package-of-beers-glassware-snacks-music-quiz-and-exclusive-playlists-to-bring-thepub-at-home

14. https://www.covidinnovations.com/home/30032020/japanese-schoolchildren-overcomequarantine-by-organising-a-minecraft-graduation-ceremony

15. https://www.covidinnovations.com/home/07042020/business-breakthrough-university-bbtuniversity-in-japan-uses-robots-to-make-graduates-attend-ceremony

16. https://www.covidinnovations.com/home/20042020/uk-brewery-signature-brew-introduces-pubin-a-box-a-package-of-beers-glassware-snacks-music-quiz-and-exclusive-playlists-to-bring-thepub-at-home

17. https://www.covidinnovations.com/home/amsterdam-based-creative-agency-achtung-createsvirtual-office-where-employees-can-digitally-meet

18. https://www.covidinnovations.com/home/14042020/airbnb-launches-online-experiences-includingvirtual-hangouts-with-goats-and-cooking-classes

19. https://www.covidinnovations.com/home/22032020/scottish-brewery-brewdog-launches-anonline-bar-with-pub-quizzes-comedy-and-other-events

20. https://www.covidinnovations.com/home/07042020/north-american-basketball-league-nba-workson-a-players-only-2k-tournament-to-be-aired-on-a-major-network

21. https:/www.covidinnovations.com/home/01042020/mailchimp-partners-with-oscilloscope-andsxsw-to-launch-online-short-film-streams

22. https://www.covidinnovations.com/home/03042020/atp-tennis-tour-goes-virtual-with-onlinetennis-betting-powered-by-ai

23. https://www.covidinnovations.com/home/07042020/wanderble-offers-free-mindfulness-inisolation-course-to-keep-company-to-people-stuck-at-home 
JOSM 32,1

110

24. https://www.covidinnovations.com/home/31032020/mental-health-app-my-possible-self-availablefor-free-to-reduce-covid-stress-and-anxiety

25. https://www.covidinnovations.com/home/20042020/creative-art-workshop-provider-artenzenoffers-creative-therapy

26. https:/www.covidinnovations.com/home/22032020/indie-beauty-brands-goop-wander-beautyand-indie-lee-shift-to-mental-health-content

27. https://www.covidinnovations.com/home/06042020/fitness-tracking-app-stepsetgo-encouragesusers-to-walk-indoors-during-quarantine

28. https://www.covidinnovations.com/home/10042020/uk-website-moments2move-makes-you-movemore-during-the-day-to-undo-the-harm-from-prolonged-sittingk

29. https://www.covidinnovations.com/home/keep-moving-platform-provides-the-opportunity-to-rundusseldorfs-metro-marathon-individually

30. https://www.covidinnovations.com/home/08042020/beauty-retail-teams-like-deciem-and-kiehlsbecome-virtual-consultants

31. https:/www.covidinnovations.com/home/15042020/uk-based-website-medicspot-offers-remoteconsultations-with-real-time-diagnostics

32. https://www.covidinnovations.com/home/15042020/-melbourne-based-tivoli-road-bakery-sellskits-to-enable-people-bake-bread-at-home

33. https://www.covidinnovations.com/home/new-website-goodnight-zoom-allows-children-toconnect-with-isolated-seniors-for-a-remote-story-time

34. https://www.covidinnovations.com/home/new-chome-extension-vemos-enables-people-toremotely-watch-a-movie-together-in-sync-with-full-video-chat

35. https://www.covidinnovations.com/home/29032020/netflix-party-is-a-browser-extension-thatsyncs-streams-so-friends-and-families-can-watch-together

36. https://www.covidinnovations.com/home/15042020/dating-app-hinge-launches-date-from-home

37. https://www.covidinnovations.com/home/22032020/zoos-and-aquariums-in-the-us-offerlivestreams-and-virtual-educational-classes-during-lockdown

38. https://www.covidinnovations.com/home/new-website-learnfromachef-offers-online-cookingclasses-by-real-working-us-chefs

39. https://www.covidinnovations.com/home/new-website-coronavirus-chronicles-enables-peopleworldwide-to-share-their-personal-covid-story

40. https://www.covidinnovations.com/home/us-platform-futurity-creates-live-digital-archive-ofpeoples-experiences-during-the-covid-times

41. https://www.covidinnovations.com/home/07042020/dallas-bakers-now-offer-creative-covidinspired-treats-to-attract-customers

42. https://www.covidinnovations.com/home/23042020/unfinished-stories-platform-collectsexperiences-of-students-during-covid

43. https://www.covidinnovations.com/home/15042020/european-parliament-opens-doors-tohomeless-and-vulnerable-in-brussels-and-strasbourg

44. https://www.covidinnovations.com/home/08042020/france-will-offer-hotel-rooms-for-domesticviolence-victim-as-numbers-soar

45. https://www.covidinnovations.com/home/10042020/facebook-releases-messaging-app-tunedallowing-couples-to-stay-more-connected

46. https://www.covidinnovations.com/home/15042020/german-cities-redraw-road-markings-to-helpcyclists-with-social-distancing 
47. https://www.covidinnovations.com/home/08042020/homeleisure-wear-has-infiltrated-all-cornersof-young-affluent-chinese-recent-wardrobes

48. https://www.covidinnovations.com/home/09042020/self-service-technologies-are-rising-in-china

\section{References}

Antons, D. and Breidbach, C.F. (2018), "Big data, big insights? Advancing service innovation and design with machine learning”, Journal of Service Research, Vol. 21 No. 1, pp. 17-39.

Baden-Fuller, C. and Teece, D.J. (2020), "Market sensing, dynamic capability, and competitive dynamics", Industrial Marketing Management, Vol. 89 August, pp. 105-106, doi: 10.1016/j. indmarman.2019.11.008.

Batat, W. (2020), "How Michelin-starred chefs are being transformed into social bricoleurs? An online qualitative study of luxury foodservice during the pandemic crisis", Journal of Service Management, Vol. ahead-of-print No. ahead-of-print, doi: 10.1108/JOSM-05-2020-0142.

Cortez, R.M. and Johnston, W.J. (2020), "The Coronavirus crisis in B2B settings: crisis uniqueness and managerial implications based on social exchange theory", Industrial Marketing Management, Vol. 88, July, pp. 125-135.

Drucker, P.F. (1974), Management: Tasks, Practices, Responsibilities, William Heinemann, London.

Feng, C., Ma, R. and Jiang, L. (2020), "The impact of service innovation on firm performance: a metaanalysis", Journal of Service Management, Vol. ahead-of-print No. ahead-of-print, doi: 10.1108/ JOSM-03-2019-0089.

Finsterwalder, J. and Kuppelwieser, V.G. (2020), "Equilibrating resources and challenges during crises: a framework for service ecosystem wellbeing, Journal of Service Management, Vol. ahead-ofprint No. ahead-of-print, doi: 10.1108/JOSM-06-2020-0201.

Furrer, O., Kerguignas, J.Y., Delcourt, C. and Gremler, D.D. (2020), "Twenty-seven years of service research: a literature review and research agenda", Journal of Services Marketing, Vol. 34 No. 3, pp. 299-316.

Gustafsson, A., Snyder, H. and Witell, L. (2020), "Service innovation: a new conceptualization and path forward", Journal of Service Research, Vol. 23 No. 2, pp. 111-115.

Hamel, G. and Prahalad, C.K. (1994), "Competing for the future”, Harvard Business Review, Vol. 72 No. 4, pp. 122-128.

Heinonen, K., Strandvik, T. and Voima, P. (2013), "Customer dominant value formation in service", European Business Review, Vol. 25 No. 2, pp. 104-123.

Helkkula, A., Kowalkowski, C. and Tronvoll, B. (2018), "Archetypes of service innovation: implications for value cocreation”, Journal of Service Research, Vol. 21 No. 3, pp. 284-301.

Kabadayi, S., O'Connor, G.E. and Tuzovic, S. (2020), "Viewpoint: the impact of coronavirus on service ecosystems as service mega-disruptions", Journal of Services Marketing, Vol. ahead-of-print No. ahead-of-print, doi: 10.1108/JSM-03-2020-0090.

Klaus, Ph. and Manthiou, A. (2020), "Applying the EEE customer mindset in luxury: reevaluating customer experience research and practice during and after corona", Journal of Service Management, Vol. ahead-of-print No. ahead-of-print, doi: 10.1108/JOSM-05-2020-0159.

Kowalkowski, C. and Witell, L. (2020), “Typologies and frameworks in service innovation”, in Bridges, E. and Fowler, K. (Eds), The Routledge Handbook Of Service Research Insights and Ideas, Routledge.

Lang, B., Dolan, R., Kemper, J.A. and Northey, G. (2020), "Prosumers in times of crisis: definition, archetypes and implications", Journal of Service Management.

Levitt, T. (1960), "Marketing myopia”, Harvard Business Review, Vol. 38 No. 4, pp. 45-56. 
JOSM

32,1

112
Nenonen, S. and Storbacka, K. (2020), "Don't adapt, shape! Use the crisis to shape your minimum viable system-And the wider market”, Industrial Marketing Management, Vol. 88, pp. 265-271.

Payne, A., Frow, P., Steinhoff, L. and Eggert, A. (2020), "Toward a comprehensive framework of value proposition development: from strategy to implementation", Industrial Marketing Management, Vol. 87, May, pp. 244-255.

Sheth, J. (2020), "Impact of covid-19 on consumer behavior: will the old habits return or die?", Journal of Business Research, Vol. 117, September, pp. 280-283.

Snyder, H., Witell, L., Gustafsson, A., Fombelle, P. and Kristensson, P. (2016), "Identifying categories of service innovation: a review and synthesis of the literature", Journal of Business Research, Vol. 69 No. 7, pp. 2401-2408.

Teece, D.J. (2007), "Explicating dynamic capabilities: the nature and microfoundations of (sustainable) enterprise performance", Strategic Management Journal, Vol. 28 No. 13, pp. 1319-1350.

Tuzovic, S. and Kabadayi, S. (2020), "The influence of social distancing on employee wellbeing: a conceptual framework and research agenda", Journal of Service Management, Vol. ahead-ofprint No. ahead-of-print, doi: 10.1108/JOSM-05-2020-0140.

\section{Corresponding author}

Kristina Heinonen can be contacted at: kristina.heinonen@hanken.fi

For instructions on how to order reprints of this article, please visit our website: 